\title{
Age and sex differences in plasma homocysteine, choline and betaine status in Seychellois children and young adults
}

\author{
M. S. Barnes ${ }^{1}$, A. McAfee ${ }^{1}$, M. P. Bonham ${ }^{1}$, E. M. McSorley ${ }^{1}$, J. M. W. Wallace ${ }^{1}$, G. J. Myers ${ }^{2}$, \\ P. W. Davidson ${ }^{2}$, S. W. Thurston ${ }^{2}$, C. F. Shamlaye ${ }^{3}$, Per M. Ueland ${ }^{4}$ and J. J. Strain ${ }^{1}$ \\ ${ }^{1}$ Northern Ireland Centre for Food and Health (NICHE), University of Ulster, Coleraine BT52 1SA, UK, ${ }^{2}$ School of \\ Medicine and Dentistry, University of Rochester, USA, ${ }^{3}$ Ministry of Health, Seychelles and ${ }^{4}$ Section for Pharmacology, \\ Institute of Medicine, University of Bergen, Norway
}

Homocysteine is an amino acid that is converted to Met via the remethylation pathway which requires betaine and choline ${ }^{(1)}$. Elevated total homocysteine (tHcy) concentrations may be an independent predictor of CVD and studies have shown that serum betaine and choline concentrations are inversely correlated with tHcy concentrations ${ }^{(2)}$.

We have previously reported tHcy concentrations of pregnant Seychellois women ${ }^{(3)}$; however, tHcy concentrations in other sub-groups from this population have not been investigated. Therefore, the aim of this study was to assess tHcy and plasma concentrations of related metabolites in children and young adults living in the Republic of Seychelles.

A total of 237 children aged 5 years and 512 young adults aged 19-20 years were recruited as part of the Seychelles Child Development Studies. Plasma tHcy, Met, free choline and betaine concentrations were assessed using liquid chromatography mass spectrometry/mass spectrometry by BeVital Laboratories, Bergen, Norway. Differences between the two age groups and between sexes were determined by independent samples $t$-test using logarithmically transformed values.

Plasma tHcy and Met concentrations were significantly higher and choline and betaine concentrations were significantly lower in young adults compared to 5-year-old children (all $P<0.0001$ ). Significant sex differences were observed: males had significantly higher concentrations of all metabolites than females; albeit these sex differences were only evident in the 19-20-year-old age group.

\begin{tabular}{lcccc}
\hline & ALL & Males & Females & $P$-value \\
\hline 5 year olds & $(n$ 237) & $(n 123)$ & $(n 114)$ & \\
tHcy & $6.03(4.18,8.81)$ & $6.05(4.27,8.85)$ & $2.98(3.70,8.83)$ & 0.755 \\
Met & $23.20(15.09,39.42)$ & $9.70(14.92,40.88)$ & $23.60(15.25,38.58)$ & 0.821 \\
Free choline & $9.05(6.25,13.16)$ & $41.90(29.86,59.66)$ & $46.45(31.70,64.78)$ & 0.847 \\
Betaine & $44.00(30.50,63.44)$ & $(n 240)$ & $(n 272)$ & $<.001$ \\
19-20-year olds & $(n 512)$ & $11.50(8.07,21.49)$ & $9.42(6.22,14.91)$ & $<0.0001$ \\
tHcy & $10.30(6.75,17.84)$ & $33.20(26.11,42.39)$ & $26.70(20.20,35.24)$ & $<0.0001$ \\
Met & $30.20(21.57,39.94)$ & $7.97(5.68,10.30)$ & $6.75(5.18,9.71)$ & $<0.0001$ \\
Free choline & $7.36(5.36,10.20)$ & $38.60(27.24,55.59)$ & $30.30(15.20,45.11)$ & $<0.0001$ \\
Betaine & $34.00(17.40,53.20)$ & &
\end{tabular}

Results are median (5th, 95th percentiles) and are presented as $\mu \mathrm{mol} / \mathrm{l}$.

In conclusion, age and sex differences in plasma tHcy concentrations and related metabolites were evident in a group of children and young adults from Seychelles. These results concur with findings from previous studies which have observed significant sex differences in homocysteine metabolism but only in children older than 15 years ${ }^{(4,5)}$. It is thought that increases in oestrogen protect against the accumulation of tHcy, possibly through different homocysteine remethylation rates ${ }^{(6)}$.

This work was supported by grants nos. PO1 ES01248, RO1 ES008442, 2 T 32 ES007271, PO ES01247, 5-R01-ES010219 and 2-T32-ES007271 from the US National Institute of Environmental Health Sciences, National Institutes of Health, the Government of Seychelles and by the EU through its Sixth Framework Programme for RTD (contract no FOOD-CT-2006-016253).

1. Zeisel SH \& Blusztajn JK (1994) Annu Rev Nutr 14, 269-296.

2. Velzing-Aarts FV, Holm PI, Fokkema RM et al. (2005) Am J Clin Nutr 81, 1383-1389.

3. Wallace JM, Bonham MP, Strain JJ et al, (2008) Am J Clin Nutr 87, 391-397.

4. Kerr MA, Livingstone B, Bates CJ et al. (2009) Pediatrics 123, 627-635.

5. van Beynum IM, den Heijer M, Thomas CM et al. (2005) Am J Clin Nutr 81, 1110-1116.

6. Fukagawa NK, Martin JM, Wurthamnn A et al. (2000) Am J Clin Nutr 72, 22-29. 